\title{
A Multichannel Medication Adherence Intervention Influences Patient and Prescriber Behavior
}

\author{
R. Scott Leslie, MPH, PhD; Todd Gilmer, PhD; Loki Natarajan, PhD; and Melbourne Hovell, PhD, MPH
}

\section{ABSTRACT}

BACKGROUND: The Centers for Medicare \& Medicaid Services (CMS) Medicare Health Plan Quality and Performance Ratings program, or Star Ratings program, includes 3 medication adherence outcome measures (Medication Adherence for Diabetes Medications, Medication Adherence for Hypertension, and Medication Adherence for Cholesterol), which contribute to approximately $31 \%$ of a Medicare Advantage prescription drug (MA-PD) plan's Part $D$ summary rating and $12 \%$ of its overall star rating (a weighted summary of a plan's Part $C$ and Part $D$ ratings). MA-PD plans have been increasing their adherence intervention efforts as an approach to improving beneficiaries' medication adherence and the plan's quality performance ratings. However, few evaluations have examined the effects of these interventions on medication adherence and performance ratings.

OBJECTIVE: To assess the impact of a quasi-experimental multichannel adherence intervention on beneficiaries' medication adherence and health plan quality performance measures for 2 MA-PD plans. The intervention included a daily prescriber-directed 90 -day retail refill component and a weekly member-directed refill reminder component.

METHODS: Members filling 1 or more medications assessed by the 3 CMS star ratings adherence measures (oral antidiabetics [DM], antihypertensives [HTN], and statins [CHOL]) were identified for a 2-component intervention starting in April 2013. The retail-based 90-day refill component sent populated 90-day prescription letters via fax to prescribers of members who had filled a 30-day prescription. One fax per member-medication instance was sent and included the option to fax approval of a new 90-day prescription. For prescribers who approved, members were notified that a 90-day refill was available at their retail pharmacies. The refill reminder component used weekly scans of pharmacy claims to identify members' refill patterns. Reminder letters were sent to members 7 days late to refill. An intent-to-treat approach was used to assess intervention effectiveness. Pharmacy claims and health plan enrollment data were used to calculate adherence among members enrolled 1 year pre- and postintervention start (April 2013) for the intervention group and a comparator group that consisted of 4 MA-PD plans not implementing an adherence intervention. Adherence was estimated by the proportion of days covered (PDC) and generalized linear models were fit to calculate difference-in-difference (DID) estimators to control for demographics, comorbidity, and changes in adherence over the study period. To estimate the impact of the intervention on health plan quality performance, 2013 and 2014 CMS star ratings for the respective 2012 and 2013 measurement years were compared by group.

RESULTS: During the first year of the intervention, 1,344 prescribers representing 6,701 members were faxed 15,284 populated prescription letters. Prescriber response rate was $53.7 \%$ and approval rate (approved letters of total sent) was $47.3 \%$. An average of 539 refill reminder letters were sent per week. DID estimators showed positive influence of the intervention on adherence to HTN and CHOL. For the intervention group, adherence increased 2.0 percentage points $(P<0.001)$ for HTN and 1.8 percentage points $(P<0.001)$ for $\mathrm{CHOL}$, relative to the control group. The odds of achieving adherence $(P D C \geq 80 \%)$ were greater in the intervention group compared with control for HTN (ratio of odds ratio $[R 0 R]=1.334$; $95 \% \mathrm{Cl}=1.203-1.479)$ and for $\mathrm{CHOL}(\mathrm{ROR}=1.247 ; 95 \% \mathrm{Cl}=1.132-1.374)$. For the 2 plans implementing the intervention, CMS-published adherence rates for DM, HTN, and CHOL increased from 2012 to 2013 by an average $5.5,6.0$, and 7.0 percentage points, respectively, compared with the control group (3.5, 2.0, and 1.8 percentage points, respectively).

CONCLUSIONS: This study found increases in adherence to HTN and CHOL in 2 MA-PD plans implementing a combined prescriber and patient-directed intervention. MA-PD plans can use broad multichannel interventions to address common adherence barriers and as an approach to improving members' adherence to maintenance medications and CMS quality performance ratings.

J Manag Care Spec Pharm. 2016;22(5):526-38

Copyright $\odot 2016$, Academy of Managed Care Pharmacy. All rights reserved.

\section{What is already known about this subject}

The Centers for Medicare \& Medicaid Services (CMS) Medicare Health Plan Quality and Performance Ratings program, or Star Ratings program, provides financial reinforcement to Medicare Advantage prescription drug plans for increasing medication adherence in their populations.

Patient counseling, lower copayments, refill reminders, extended days supply, and simplified regimens are strategies for improving medication adherence.

Systematic literature reviews and medication adherence advisory committees recommend that additional research assess interventions applied to large patient populations.

\section{What this study adds}

A broad, multichannel medication adherence intervention can address common adherence barriers, such as forgetfulness and medication access, to effectively increase adherence rates among entire memberships.

Health plans can implement broad interventions to influence their CMS quality performance ratings.

- A prescriber-directed retail 90-day intervention can effectively influence prescribing patterns of maintenance medications. 
$\mathrm{T}$ he Centers for Disease Control and Prevention estimates the prevalence of diabetes, hypertension, and hyperlipidemia in the elderly at $25.9 \%, 69.7 \%$, and $58.2 \%$, respectively. ${ }^{1,2,3}$ The prevalence of these diseases is projected to rise with the aging of the baby boom generation. The elderly population is forecasted to be nearly $17 \%$ of the total U.S. population by $2020 ., 5$ Pharmacologic treatment is fundamental to the management of these conditions, and suboptimal adherence to prescribed therapies threatens treatment effectiveness. Consequences of poor adherence include increased health care utilization and costs and poorer clinical outcomes. ${ }^{6-11}$ Among Medicare beneficiaries in 2013, adherence rates for medication classes used to treat diabetes, hypertension, and hyperlipidemia were lower $(77 \%, 79 \%$, and $74 \%$, respectively) than the recommended adherence threshold of $\geq 80 \%{ }^{12}$

The Centers for Medicare \& Medicaid Services (CMS) developed the Medicare Health Plan Quality and Performance Ratings program, or Star Ratings program, to evaluate quality performance and allow beneficiaries to compare cost and quality of available Medicare Advantage prescription drug (MA-PD) plans and prescription drug plans. Each year MA-PD plans with more than 500 beneficiaries receive an overall star rating, which is a weighted average of a Part $C$ domain summary rating and a Part D domain summary rating. For the 2015 star ratings, the Part C and Part D summary ratings consisted of 33 and 13 performance measures, respectively.

Star ratings are released on Medicare's Plan Finder website each October before Medicare's annual fall open enrollment period and have been associated with increased enrollment and Medicare reimbursements. A 2012 study quantified the average value of increased star ratings and found that an overall star rating increase of 1 was associated with a 9.5\% increased likelihood of enrolling new beneficiaries. ${ }^{13}$

In November 2010, CMS implemented a demonstration project in provision with the 2010 Patient Protection and Affordable Care Act that tied quality bonus payments (QBPs) to overall star ratings as incentives to promote quality among Medicare Part D contracts. ${ }^{14}$ In 2012, Medicare reimbursements including QBPs totaled $\$ 3.1$ billion. ${ }^{15}$ For the 2015 CMS star rating release, the 13 Part D domain star rating measures include 3 patient safety outcome measures (Medication Adherence for Diabetes Medications [D11], Medication Adherence for Hypertension [D12], and Medication Adherence for Cholesterol [D13]) that carry triple the weight of other process measures. These 3 measures can contribute up to $12 \%$ of a health plan contract's overall star rating and $31 \%$ of its Part D summary rating. ${ }^{12}$

Intervention strategies to improve medication adherence vary by mode of delivery (e.g., in-person, mail, phone, etc.), frequency of administration, and target audience (e.g., patient or provider). Randomized controlled trials describe positive effectiveness of refill reminder interventions among small, select populations, ${ }^{16-19}$ and observational studies report higher adherence in patients receiving extended days supply. ${ }^{20,21}$ Quasi-experimental studies demonstrate the usefulness of pharmacy-based interventions limited to populations from select pharmacies ${ }^{22}$ and interventions among members enrolled in medication therapy management programs. ${ }^{23}$ However, there is insufficient research describing the effects of adherence interventions targeting chronic disease medications applied to entire health plan populations. Evidence of population-level adherence interventions within usual, routine clinical care settings can guide pharmacy directors and managed care professionals to adopt innovative means of increasing medication adherence for their whole membership population.

In April 2013, 2 MA-PD plans under contract with MedImpact Healthcare Systems, implemented a multichannel medication adherence intervention to increase member adherence to the 3 medication classes characterized by the CMS plan performance ratings. The 2-component adherence intervention included a prescriber-directed, retail-based, 90-day prescription component and a member-directed refill reminder component. The objective of this research was to assess the effectiveness of this intervention among Medicare beneficiaries of these 2 health plans.

We hypothesized that adherence rates would increase among beneficiaries enrolled in these health plans relative to a comparison group of beneficiaries enrolled in health plans that were not conducting adherence interventions. Findings from this evaluation could assist pharmacy directors and quality teams of MA-PD plans when they decide on potential interventions based on their quality performance goals and available resources.

\section{Methods}

\section{Intervention Description}

The multichannel medication adherence intervention identified members filling medications included in the CMS quality performance adherence ratings. Specifically, these medications comprised noninsulin hypoglycemic agents (biguanides, thiazolidinediones, sulfonylureas, dipeptidyl peptidase-4 inhibitors, incretin mimetics, and metglitinides), renin-angiotensin system antagonists (a subset of HTN consisting of angiotensinconverting enzyme inhibitors, angiotensin II receptor blockers, and direct renin inhibitors), and antihyperlipidemics (statins). The intervention included 2 components starting in April 2013: a 90-day refill component and a refill reminder component. The 90-day refill component was a prescriberdirected fax program that identified members who filled at least 1 prescription of 30 days supply for any of the targeted medications in the previous 3-month period. Prescribers of the most recent prescription for each targeted medication were faxed a letter containing a populated 90-day prescription for members eligible for 90-day refills at retail pharmacies. One letter fax for each member-medication combination was sent to the prescribers, resulting in prescribers receiving more than 


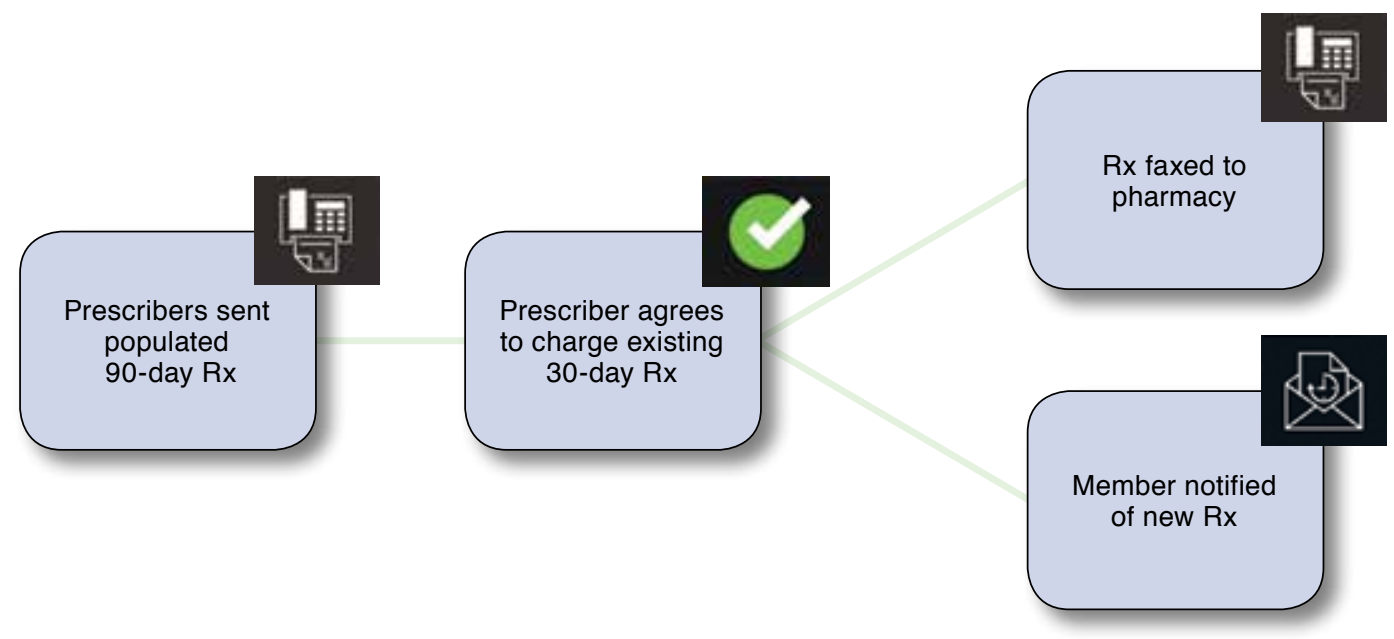

$R x=$ prescription .

1 letter for a given member (Figure 1). Prescribers were asked to respond via fax.

For those prescribers who approved of the prescription, the new 90-day prescription was sent to the pharmacy for automatic processing on the date of the member's next scheduled refill. Members were then notified by letter that their prescription was changed to a 90-day supply and would be available at their retail pharmacy. Prescribers who did not respond within 21 days were faxed a second letter. Prescribers were retargeted if their patients refilled a 30-day prescription instead of the proposed 90-day prescription. Denying prescribers were not requested to reconsider at a later date.

The refill reminder component was a member-directed letter program. Weekly scans and analysis of prescription claims data identified members who were late in refilling each targeted medication (Figure 2). The fill date and corresponding days supply data fields for members' most recent claims were used to calculate the end of medication supply and potential days late to refill. CMS-approved refill reminder letters were sent to members late in refilling by 7 days. Letters explained the importance of medication adherence and listed medication name and last fill date. Members received a letter for each late refill instance, and therefore members could receive multiple letters for 1 or more medications.

\section{Study Design and Population}

This study employed an historical prospective evaluation of the above-described quasi-experimental multichannel medication adherence intervention using a pharmacy claims database. The study population comprised enrolled beneficiaries of 6 MA-PD plan contracts (health plans) using the 3 medication classes of interest during the 2-year study period (April
2012 to March 2014). The intervention group was delivered to 2 health plans with a combined membership of approximately 24,000 members. Four health plans with a combined membership of approximately 75,000 members served the control group. Health plan account teams and pharmacy directors were contacted to rule out possible other interventions conducted during the study period by the health plans selected for the comparison group.

\section{Study Measures}

Outcomes. The primary outcomes were member and health plan-level adherence rates. Member adherence rates were calculated as the proportion of days covered (PDC) by medication using specifications from the CMS Medicare Health \& Drug Plan Quality and Performance Ratings 2014 Part C \& Part D Technical Notes ${ }^{24}$ (released September 27, 2013) and the Acumen Patient Safety Analysis Report User Guide (data on file, Acumen, Patient Safety Report, July 2014. Available by authorized use). Members aged 18 years and older with 2 or more prescription claims for the target medications and at least 91 days of continuous eligibility were included in the analysis. In accordance with CMS measurement specifications, members with a prescription claim for insulin were excluded from the diabetes adherence assessment.

PDC was measured from the first claim in the measurement period (index date) to the end of the measurement period or date of member disenrollment. Days of medication coverage (PDC numerator) was calculated using prescription fill dates and days supply elements of prescription claims within each member's measurement period (PDC denominator) ${ }^{25}$ Adherence for each medication class was calculated as both a continuous variable, ranging from $1 \%$ to $100 \%$, and a 


\section{FIGURE 2 Refill Reminder Sequence of} Communications

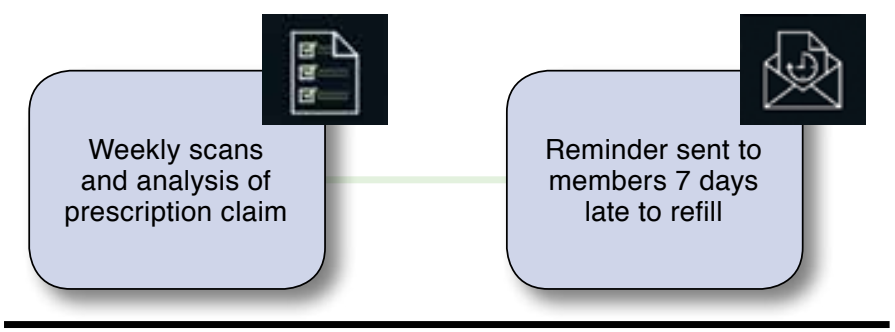

binary measure (PDC $\geq 80 \%$ ), based on the adherence threshold used by CMS. For scenarios in which refills occurred before members exhausted their current medication supply, the overlapping days supply between fills was carried forward and counted only once in the numerator. Medication coverage occurring after the measurement year was not counted in the PDC numerator. Adherence was measured for the 1 year prior (April 2012 to March 2013) and the first year after (April 2013 to March 2014) the intervention start date (April 2013).

CMS-published health plan performance ratings were used to assess change in health plan quality performance. Changes in adherence rates were calculated as the difference between adherence rates reported for the 2012 and 2013 measurement years (corresponding 2014 and 2015 star ratings), which approximates the pre- to postintervention periods.

Additional Study Measures. Sociodemographic covariates (age, sex, and low-income subsidy [LIS] status) were ascertained from member eligibility files. Age was calculated from the date of the first claim in the baseline period. An indicator variable was created to identify members who received an LIS at any time during the study period. This covariate is pertinent because CMS-published adherence rates are lower for this subgroup of the Medicare population, ${ }^{24}$ and previous studies describe greater comorbidity among LIS beneficiaries compared with non-LIS beneficiaries. ${ }^{26,27}$ Higher illness burden is a risk factor for poor adherence, and CMS is currently assessing the potential influence of LIS and socioeconomic status on quality performance measures. ${ }^{28}$

Additional control variables included indicators for being new to therapy and receiving 90-day refills in the preperiod plus ordinal variables measuring the number of baseline comorbidities and the number of specific conditions targeted by the intervention. Members were identified as new to therapy if they had no history of a prescription claim for the respective medication class in the 6 months prior to the index date. Members were identified as receiving 90-day refills if they filled 1 or more prescriptions for a 90 days supply in the preperiod.

Comorbidities in the baseline period were identified using the Medicaid Rx model. Medicaid Rx is a pharmacy-based classification system used to risk-adjust capitated payments for Medicaid health plans. ${ }^{29}$ The model uses prescription claims to identify 45 disease states based on National Drug Code numbers. This risk adjuster was selected over other pharmacybased risk adjusters because $20.8 \%$ of the study population comprised dual-eligible Medicare and Medicaid beneficiaries. An ordinal scale variable was created to identify the number of comorbidities: <3, 3-4, 5-6, 7-8, and 9+. Members could be identified for the intervention for up to 3 medication classes; therefore, a count variable from 1 to 3 was calculated to account for members receiving multiple intervention exposures.

\section{Statistical Methods}

All analyses were performed using SAS software package 9.4 (SAS Institute, Cary, NC). Descriptive statistics were calculated for independent and outcome variables and tabulated by treatment group and medication class. Estimations of group differences were evaluated by t-tests for continuous variables and chi-square tests for categorical variables. Cross-tabulations showing between-group differences in baseline measurements were used to identify potential confounders. Univariate, bivariate, and multivariate analyses were performed using twosided hypothesis tests with a 0.05 level of significance.

Adherence rates (continuous outcome) and proportion of adherent members (binary outcome) were measured in 1-year periods before and after the intervention start date (April 2013). The preperiod spanned April 2012 to March 2013, and the postperiod spanned April 2013 to March 2014. The analysis included only those members with values in both the pre- and postintervention periods. Change in adherence rates and proportion of adherent members from pre- to postintervention periods were calculated. Unadjusted differences in the changes in adherence between groups were compared and assessed for statistical significance.

Changes in medication adherence associated with the multichannel medication adherence intervention were examined using an intent-to-treat, difference-in-difference (DID) design (i.e., pre-post study design with a contemporaneous control group). This approach mitigates the risk of attributing a confounded change in the secular trends to the intervention. Secular trends in medication adherence may arise due to several adherence-promoting campaigns initiated by national organizations over the last 5 years..$^{30-34}$ These programs and the addition of the 3 adherence-related performance measures to the CMS Star Ratings program in 2010 may have increased patient, prescriber, and pharmacist awareness and knowledge of medication adherence over the study period.

A main assumption of the DID approach is the parallel trend assumption, which fails if factors other than the intervention affected adherence in the groups differentially. To test this assumption, adherence to another maintenance medication class, antidepressants, was measured across the study 
TABLE 1 Member Demographics and Clinical Characteristics

\begin{tabular}{|c|c|c|c|c|c|c|c|c|c|}
\hline & \multicolumn{3}{|c|}{ Oral Antidiabetics, $n=5,421$} & \multicolumn{3}{|c|}{ Antihypertensives, $n=19,520$} & \multicolumn{3}{|c|}{ Statins, $\mathbf{n}=19,244$} \\
\hline & Intervention & Control & $P$ Value & Intervention & Control & $P$ Value & Intervention & Control & $P$ Value \\
\hline Member count, $\mathrm{n}$ & 1,277 & 4,144 & & 4,787 & 14,733 & & 4,382 & 14,862 & \\
\hline Female, $\%$ & 51.8 & 53.9 & 0.180 & 53.6 & 56.9 & $<0.001$ & 51.8 & 54.9 & $<0.001$ \\
\hline New to therapy, ${ }^{\text {a } \%}$ & 21.5 & 22.4 & 0.484 & 20.9 & 20.0 & 0.155 & 21.8 & 19.4 & $<0.001$ \\
\hline 90-day refill, \% & 59.6 & 70.0 & $<0.001$ & 64.4 & 71.6 & $<0.001$ & 65.7 & 72.8 & $<0.001$ \\
\hline Low-income subsidy, \% & 41.4 & 18.9 & $<0.001$ & 34.6 & 15.9 & $<0.001$ & 32.7 & 16.2 & $<0.001$ \\
\hline Age, years, mean (SD) & $71.3(8.8)$ & $73.7(8.7)$ & $<0.001$ & $71.8(9.2)$ & $74.6(8.7)$ & $<0.001$ & $71.3(8.5)$ & $73.8(8.5)$ & $<0.001$ \\
\hline \multicolumn{3}{|l|}{ Age group, years, \% } & $<0.001$ & & & $<0.001$ & & & $<0.001$ \\
\hline$<54$ & 4.6 & 3.0 & & 4.8 & 2.2 & & 3.7 & 2.5 & \\
\hline $55-64$ & 12.9 & 6.8 & & 12.0 & 5.5 & & 11.9 & 5.4 & \\
\hline $65-74$ & 53.6 & 49.8 & & 51.5 & 47.9 & & 54.1 & 48.9 & \\
\hline $75+$ & 28.9 & 40.4 & & 31.6 & 44.4 & & 30.4 & 43.2 & \\
\hline \multicolumn{3}{|c|}{ Number of target medication classes, ${ }^{b} \%$} & 0.640 & & & $<0.001$ & & & 0.090 \\
\hline 1 & 13.7 & 12.1 & & 41.2 & 34.6 & & 38.5 & 36.0 & \\
\hline 2 & 39.2 & 35.3 & & 45.4 & 50.0 & & 47.0 & 48.5 & \\
\hline 3 & 47.1 & 52.6 & & 13.4 & 15.3 & & 14.5 & 15.4 & \\
\hline \multicolumn{3}{|l|}{ Comorbidity count,c \% } & 0.161 & & & 0.008 & & & 0.078 \\
\hline$<3$ & 29.8 & 30.9 & & 41.7 & 42.1 & & 45.6 & 44.2 & \\
\hline $3-4$ & 40.5 & 40.6 & & 35.3 & 35.9 & & 31.9 & 34.2 & \\
\hline $5-6$ & 20.8 & 20.5 & & 16.7 & 16.0 & & 16.1 & 15.4 & \\
\hline $7-8$ & 6.6 & 6.5 & & 4.8 & 4.8 & & 5.0 & 4.9 & \\
\hline $9+$ & 2.3 & 1.5 & & 1.5 & 1.2 & & 1.6 & 1.3 & \\
\hline
\end{tabular}

a Defined as absence of prescription claim for targeted medication class in 1-year baseline (preintervention) period.

${ }^{b}$ Members could be identified for intervention by more than 1 medication class.

${ }^{c}$ Comorbidity count estimated by Medicaid Rx.

$S D=$ standard deviation

period to assess possible differences in underlying trends between groups.

For the dichotomous outcome (PDC $\geq 80 \%$ ), the GENMOD procedure in SAS was used to fit logistic regression models for each medication class. Generalized estimating equations $s^{35,36}$ were selected over traditional regression models (which assume independence between observations) to account for correlated repeated measures data (pre- and postperiod measurements for each member) and clustering effects (potential treatment similarities within a health plan). For each medication class, logistic regressions modeled the probability of achieving adherence using the following equation,

$\operatorname{logitP}($ Adherence $)=\beta_{0}+\beta_{1}$ Group $_{i}+\beta_{2}$ Time $_{i}+\beta_{3}(\text { Group } \text { Time })_{\mathrm{i}}+\beta_{\mathrm{k}} \mathrm{X}_{\mathrm{ki}}+\varepsilon_{\mathrm{i}}$

where adherence to therapy (PDC $\geq 80 \%$ ), the dependent variable, was modeled by a treatment group indicator (Group), a time indicator (Time), a Group $\times$ Time interaction term, and the following available variables known to affect adherence $\left(X_{k}\right)$ : age, sex, new to therapy, number of targeted medication classes, number of comorbid conditions, receiving 90-day refills in the preperiod, and LIS status. Coefficients of all models were reported.

The DID estimator assessed the intervention effect as the difference in medication adherence between the intervention and control groups during the intervention, adjusting for the difference between treatment groups before the intervention and accounting for natural adherence trends during the 2-year study period. A positive, significant coefficient on $\beta_{3}$ indicates a positive intervention effect. We interpreted interaction terms in our nonlinear link function models based on work by Diggle et al. (2002). ${ }^{37}$

In logistic models, odds ratios (ORs) are calculated as the exponential of parameter estimates. The exponent of the DID parameter is a ratio of odds ratio (ROR), where in our example the OR of achieving adherence in the postperiod versus the preperiod for the treatment group is divided by the OR of adherence in the postperiod versus the preperiod for the control group. Specific odds of adherence in the postperiod relative to the preperiod for the treatment and control groups were calculated separately by changing the reference category in the models. This method was used in an evaluation of the effects of Part D drug coverage on medication adherence among Medicare populations. ${ }^{38}$

Similar models were fit for the continuous adherence outcome. PDC distributions are commonly nonnormal with a large proportion of patients with high PDC measurements and a low proportion of patients with low PDC values. The GLMMIX procedure was used to fit generalized linear mixed 


\begin{tabular}{|c|c|c|c|c|c|c|c|c|c|}
\hline & \multicolumn{3}{|c|}{ Oral Antidiabetics } & \multicolumn{3}{|c|}{ Antihypertensives } & \multicolumn{3}{|c|}{ Statins } \\
\hline & $\begin{array}{c}\text { Intervention } \\
\mathbf{n}=1,277\end{array}$ & $\begin{array}{c}\text { Control } \\
\mathrm{n}=4,144\end{array}$ & $P$ Value & $\begin{array}{c}\text { Intervention } \\
\mathbf{n}=4,787\end{array}$ & $\begin{array}{c}\text { Control } \\
\mathrm{n}=14,733\end{array}$ & $P$ Value & $\begin{array}{c}\text { Intervention } \\
\mathbf{n}=4,382\end{array}$ & $\begin{array}{c}\text { Control } \\
\mathrm{n}=14,862\end{array}$ & $P$ Value \\
\hline \multicolumn{10}{|l|}{ PDC, mean } \\
\hline Preperiod, a $\%$ & 87.6 & 89.5 & & 88.5 & 90.8 & & 87.2 & 88.9 & \\
\hline Postperiod,, $\mathrm{b} \%$ & 89.1 & 90.3 & & 89.9 & 90.2 & & 88.5 & 88.4 & \\
\hline Difference (preperiod to postperiod)c & 1.5 & 0.8 & 0.206 & 1.4 & -0.6 & $<0.001$ & 1.3 & -0.5 & $<0.001$ \\
\hline Difference-in-difference $^{\mathrm{d}}$ & \multicolumn{2}{|c|}{+0.7} & & \multicolumn{2}{|c|}{+2.0} & & \multicolumn{2}{|c|}{+1.8} & \\
\hline \multicolumn{10}{|l|}{ PDC $\geq 80, \%$} \\
\hline Preperiod, a \% & 78.6 & 80.3 & & 80.2 & 85.2 & & 78.1 & 81.1 & \\
\hline Postperiod,b \% & 81.7 & 83.6 & & 82.8 & 83.9 & & 80.9 & 80.3 & \\
\hline Difference (preperiod to postperiod)c & 3.1 & 3.3 & 0.178 & 2.6 & -1.3 & $<0.001$ & 2.8 & -0.8 & 0.090 \\
\hline Difference-in-difference $^{\mathrm{d}}$ & \multicolumn{2}{|c|}{-0.2} & & \multicolumn{2}{|c|}{+3.9} & & \multicolumn{2}{|c|}{+3.6} & \\
\hline \multicolumn{10}{|c|}{$\begin{array}{l}\text { Note: T-tests used to assess statistical difference between treatment groups } \\
\text { categorical PDC } \geq 80 \text { outcome. } \\
\text { aPreperiod =April } 2012 \text { to March } 2013 \text {. } \\
\text { 'Postperiod =April } 2013 \text { to March } 2014 . \\
\text { 'Difference = preperiod to postperiod. } \\
\text { dDifference-in-difference=difference (intervention)-difference (control). } \\
\text { PDC= proportion of days covered. }\end{array}$} \\
\hline
\end{tabular}

models to account for this negatively skewed distribution and nesting of patients within health plans. ${ }^{39}$

As part of a post hoc analysis, we ran models on a subgroup of members targeted by the 90-day intervention component: (a) members with at least 1 previous 30-day fill (to avoid targeting members beginning therapy), and (b) those without a history of a 90-day refill (to avoid messaging members already using the 90-day benefit). Models were fit for this patient subgroup to examine differential effects of the intervention within this targeted subgroup to determine if this special subgroup replicated effects found for the whole sample.

\section{Results}

\section{Intervention Activity}

During the first year of the 90-day program (April 2013 to March 2014), a total of 1,344 prescribers, representing 6,701 members, were faxed 15,284 populated prescription letters. This total letter volume represented 9,544 unique prescriber-member-medication combinations (initial fax letters) and 5,740 reminder faxes. The prescriber response rate was $53.7 \%$. The percentage of prescribers approving new 90-day prescriptions (approval rate) was 47.3\% $(4,510 / 9,544)$. During this same period, the refill reminder program sent a total of 28,008 reminder letters to 9,938 members, for an average of 539 letters per week.

\section{Study Population}

Our analysis included a total of 28,924 unique members filling prescriptions for 1 or more of the 3 medication classes: oral antidiabetics (DM), antihypertensives (HTN), and statins
(CHOL; Table 1). Compared with members of the control group, members of the intervention group were slightly younger (using DM, 71.3 vs. 73.7, $P<0.001 ; \mathrm{HTN}, 71.8$ vs. 74.6, $P<0.001$; $\mathrm{CHOL}, 71.3$ vs. $73.8, P<0.001$ ); less likely to be female (DM, $51.8 \%$ vs. $53.9 \%, P<0.180$; HTN, $53.6 \%$ vs. $56.9 \%, P<0.001 ; \mathrm{CHOL}, 51.8 \%$ vs. $54.9 \%, P<0.001)$; and more likely to receive an LIS (DM, $41.4 \%$ vs. $18.9 \%, P<0.001$; HTN, $34.6 \%$ vs. $15.9 \%, P<0.001$; CHOL, $32.7 \%$ vs. $16.2 \%$, $P<0.001)$. The proportion of members new to therapy was similar between groups, but slightly higher among the intervention group for the CHOL class $(21.8 \%$ vs. $19.4 \%, P<0.001)$. Use of 90-days supply in the preperiod was more prevalent in the control group for all 3 targeted classes (DM, 70.0\% vs. $59.6 \%, P<0.001$; HTN, $71.6 \%$ vs. $64.4 \%, P<0.001$; CHOL, $72.8 \%$ vs. $65.7 \%, P<0.001$ ). Members using DM had the largest prevalence of the other 2 target medication classes: $47.1 \%$ of the intervention group and $52.6 \%$ of the control group with DM also filled HTN and CHOL medications.

\section{Unadjusted Changes in Adherence}

Changes in adherence rates for HTN and CHOL for the treatment group were significantly greater than the control group (Table 2). For HTN and CHOL respectively, the average changes in PDC were greater in the treatment group (1.4 vs. $-0.6, P<0.001 ; 1.3$ vs. $-0.5(P<0.001)$. The percentage of members who were identified as being adherent (PDC $\geq 80 \%$ ) to HTN and CHOL increased on average in the intervention group compared with decreases in the control group (HTN, 2.6 vs. -1.3 points, $P<0.001$; CHOL, 2.8 vs. -0.8 points, $P=0.090$ ). There was not a statistically significant difference in the pre- to 
TABLE 3 Intervention Effects on Adherence to Oral Antidiabetics

\begin{tabular}{|c|c|c|c|c|c|c|c|c|c|}
\hline \multirow[b]{3}{*}{ Variable } & \multicolumn{3}{|c|}{ PDC (Continuous) } & \multicolumn{6}{|c|}{$\mathrm{PDC} \geq 80 \%$ (Binary) } \\
\hline & \multirow[b]{2}{*}{ Coefficient } & \multirow[b]{2}{*}{ SE } & \multirow[b]{2}{*}{$P$ Value } & \multirow[b]{2}{*}{ Coefficient } & \multirow[b]{2}{*}{ SE } & \multirow[b]{2}{*}{ OR } & \multicolumn{2}{|c|}{$95 \% \mathrm{CI}$} & \multirow[b]{2}{*}{$P$ Value } \\
\hline & & & & & & & Upper & Lower & \\
\hline Female (reference: male) & -0.003 & 0.003 & 0.406 & -0.039 & 0.059 & 0.961 & 0.857 & 1.079 & 0.505 \\
\hline \multicolumn{10}{|c|}{ Age group, years (reference: $<55$ years) } \\
\hline $55-64$ & 0.034 & 0.012 & 0.004 & 0.312 & 0.190 & 1.366 & 0.941 & 1.982 & 0.101 \\
\hline $65-74$ & 0.029 & 0.011 & 0.006 & 0.191 & 0.170 & 1.210 & 0.866 & 1.690 & 0.263 \\
\hline $75+$ & 0.029 & 0.011 & 0.006 & 0.207 & 0.171 & 1.230 & 0.880 & 1.719 & 0.225 \\
\hline \multicolumn{10}{|c|}{ Comorbidity count (reference: <3) } \\
\hline $3-4$ & 0.006 & 0.003 & 0.078 & 0.100 & 0.060 & 1.106 & 0.984 & 1.242 & 0.092 \\
\hline $5-6$ & 0.005 & 0.004 & 0.277 & 0.118 & 0.076 & 1.125 & 0.969 & 1.306 & 0.121 \\
\hline $7-8$ & 0.002 & 0.006 & 0.758 & 0.063 & 0.114 & 1.065 & 0.852 & 1.332 & 0.578 \\
\hline $9+$ & -0.001 & 0.012 & 0.963 & 0.193 & 0.220 & 1.213 & 0.788 & 1.867 & 0.380 \\
\hline New to therapy & -0.019 & 0.004 & $<0.0001$ & -0.458 & 0.070 & 0.633 & 0.552 & 0.725 & $<0.0001$ \\
\hline 90-day refill & 0.059 & 0.004 & $<0.0001$ & 0.706 & 0.062 & 2.026 & 1.796 & 2.286 & $<0.0001$ \\
\hline \multicolumn{10}{|c|}{ Number of target medication classes (reference: 1 ) } \\
\hline 2 & 0.021 & 0.005 & $<0.0001$ & 0.212 & 0.085 & 1.236 & 1.047 & 1.460 & 0.013 \\
\hline 3 & 0.032 & 0.005 & $<0.0001$ & 0.411 & 0.084 & 1.508 & 1.280 & 1.777 & $<0.0001$ \\
\hline Low-income subsidy & -0.010 & 0.004 & 0.025 & -0.150 & 0.071 & 0.861 & 0.749 & 0.990 & 0.036 \\
\hline Time (reference: preperioda) & 0.004 & 0.003 & 0.097 & 0.135 & 0.051 & 1.144 & 1.035 & 1.265 & 0.009 \\
\hline Group (reference: control) & -0.009 & 0.005 & 0.059 & 0.005 & 0.081 & 1.005 & 0.858 & 1.177 & 0.951 \\
\hline Group $\times$ Time interaction ${ }^{b}$ & 0.006 & 0.005 & 0.256 & -0.033 & 0.098 & 0.967 & 0.798 & 1.172 & 0.734 \\
\hline \multicolumn{10}{|c|}{$\begin{array}{l}\text { Note: Generalized linear models used to assess statistical difference between treat } \\
\text { binary outcome. } \\
\text { aPreperiod=April } 2012 \text { to March 2013; postperiod=April } 2013 \text { to March } 2014 \text {. } \\
\text { b Group } \times \text { Time interaction variable is difference-in-difference estimator. }\end{array}$} \\
\hline
\end{tabular}

postperiod changes in DM adherence between the treatment group and control group.

\section{Adjusted Adherence Rates}

Tables 3-5 show results of DID regressions for both continuous and dichotomous outcomes. These results show that adherence to HTN and CHOL increased in the intervention group relative to the control group when accounting for correlated data due to repeated measures and controlling for patient characteristics and time trends. Adherence to HTN increased 2.0 percentage points (Group $\times$ Time interaction term; 0.020, $P<0.0001)$ in the intervention group relative to the control group (Table 4). For the binary adherence outcome model, the DID coefficient was positive and statistically significant $(0.288$, $P<0.0001)$. The exponential of this estimate was 1.334 , an ROR $(1.125 / 0.844=1.334)$, which can be interpreted as follows: The intervention group had $12.5 \%$ increased odds of achieving adherence in the postperiod compared with the year before the intervention $(\mathrm{OR}=1.125,95 \%$ confidence interval $[\mathrm{CI}]=1.028$ 1.231), and the control group had $15.6 \%$ lower odds of being adherent in the postperiod compared with before the intervention. Adherence to $\mathrm{CHOL}$ increased 1.80 percentage points (Group $\times$ Time interaction term; 0.018, $P<0.0001$ ) for the intervention group relative to the control group (Table 5).
For $\mathrm{PDC} \geq 80 \%$, the DID coefficient was positive and significant $(0.221, P<0.0001)$, translating to an ROR of 1.247 (95\% CI $=1.132-1.374)$. The intervention group had $11.3 \%$ increased odds of achieving adherence in the postperiod compared with the year before the intervention $(\mathrm{OR}=1.113,95 \%$ $\mathrm{CI}=1.022-1.213$ ), whereas the control group had $10.7 \%$ lower odds of being adherent in the postperiod compared with before the intervention $(\mathrm{OR}=0.893,95 \% \mathrm{CI}=0.849-0.938)$; the ratio of these estimates (1.113/0.893) is the DID estimate from the model.

As observed in the unadjusted analyses, there was not a statistically significant difference in the pre- to postperiod changes in DM adherence between the treatment group and control group. Across all models, receipt of a 90-day refill in the preperiod was associated with increased adherence, and being new to therapy was associated with reduced adherence.

For the 2 plans implementing the intervention, CMSpublished adherence rates increased from 2012 to 2013 by an average 5.5, 6.0, and 7.0 percentage points, respectively, for the adherence Part D measures: Medication Adherence for Diabetes, Medication Adherence for Hypertension, and Medication Adherence for Cholesterol. These increases were greater than the average changes among plans in the control group (3.5, 2.0, and 1.8 percentage points). 


\begin{tabular}{|c|c|c|c|c|c|c|c|c|c|}
\hline \multirow[b]{3}{*}{ Variable } & \multicolumn{3}{|c|}{ PDC (Continuous) } & \multicolumn{6}{|c|}{ PDC $\geq 80 \%$ (Binary) } \\
\hline & \multirow[b]{2}{*}{ Coefficient } & \multirow[b]{2}{*}{ SE } & \multirow[b]{2}{*}{$P$ Value } & \multirow[b]{2}{*}{ Coefficient } & \multirow[b]{2}{*}{ SE } & \multirow[b]{2}{*}{ OR } & \multicolumn{2}{|c|}{$95 \%$ CI } & \multirow[b]{2}{*}{$P$ Value } \\
\hline & & & & & & & Upper & Lower & \\
\hline Female (reference: male) & 0.001 & 0.002 & 0.631 & 0.0052 & 0.0331 & 1.005 & 0.942 & 1.073 & 0.8741 \\
\hline \multicolumn{10}{|c|}{ Age group, years (reference: $<55$ years) } \\
\hline $55-64$ & 0.022 & 0.006 & 0.001 & 0.2919 & 0.0996 & 1.339 & 1.102 & 1.628 & 0.0034 \\
\hline $65-74$ & 0.035 & 0.006 & $<0.0001$ & 0.5088 & 0.0902 & 1.663 & 1.394 & 1.985 & $<0.0001$ \\
\hline $75+$ & 0.035 & 0.006 & $<0.0001$ & 0.4942 & 0.0906 & 1.639 & 1.372 & 1.958 & $<0.0001$ \\
\hline \multicolumn{10}{|c|}{ Comorbidity count (reference: $<3$ ) } \\
\hline $3-4$ & -0.004 & 0.002 & 0.028 & -0.0095 & 0.0333 & 0.991 & 0.928 & 1.057 & 0.7747 \\
\hline $5-6$ & -0.009 & 0.002 & $<0.0001$ & -0.1007 & 0.0438 & 0.904 & 0.830 & 0.985 & 0.0214 \\
\hline $7-8$ & -0.019 & 0.004 & $<0.0001$ & -0.2610 & 0.0682 & 0.770 & 0.674 & 0.880 & 0.0001 \\
\hline $9+$ & -0.034 & 0.007 & $<0.0001$ & -0.3875 & 0.1196 & 0.679 & 0.537 & 0.858 & 0.0012 \\
\hline New to therapy & -0.013 & 0.002 & $<0.0001$ & -0.3381 & 0.0424 & 0.713 & 0.656 & 0.775 & $<0.0001$ \\
\hline 90-day refill & 0.053 & 0.002 & $<0.0001$ & 0.6916 & 0.0341 & 1.997 & 1.868 & 2.135 & $<0.0001$ \\
\hline \multicolumn{10}{|c|}{ Number of target medication classes (reference: 1 ) } \\
\hline 2 & 0.013 & 0.002 & $<0.0001$ & 0.2351 & 0.0337 & 1.265 & 1.184 & 1.351 & $<0.0001$ \\
\hline 3 & 0.018 & 0.003 & $<0.0001$ & 0.285 & 0.0493 & 1.330 & 1.207 & 1.464 & $<0.0001$ \\
\hline Low-income subsidy & -0.014 & 0.002 & $<0.0001$ & -0.200 & 0.0413 & 0.819 & 0.755 & 0.888 & $<0.0001$ \\
\hline Time (reference: preperioda) & -0.009 & 0.001 & $<0.0001$ & -0.1701 & 0.0287 & 0.844 & 0.797 & 0.892 & $<0.0001$ \\
\hline Group (reference: control) & -0.013 & 0.002 & $<0.0001$ & -0.2318 & 0.0446 & 0.793 & 0.727 & 0.865 & $<0.0001$ \\
\hline Group $\times$ Time interaction ${ }^{\mathrm{b}}$ & 0.020 & 0.003 & $<0.0001$ & 0.288 & 0.0528 & 1.334 & 1.203 & 1.479 & $<0.0001$ \\
\hline \multicolumn{10}{|c|}{$\begin{array}{l}\text { Note: Generalized linear models used to assess statistical difference between treatment groups for continuous PDC outcomes. Logistic regression used for PDC } \geq 80 \% \text { binary } \\
\text { outcome. } \\
\text { aPreperiod = April } 2012 \text { to March 2013; postperiod =April } 2013 \text { to March } 2014 . \\
\text { broup } \times \text { Time interaction variable is difference-in-difference estimator. } \\
C I=\text { confidence interval; OR=odds ratio; PDC= proportion of days covered; SE= standard error. }\end{array}$} \\
\hline
\end{tabular}

\section{Post Hoc Analysis}

Differences in adherence rates between groups were greater when we restricted our analysis to members without a 90 -day prescription in the preperiod. For the intervention group, adherence increased 2.27 percentage points $(P=0.020)$ for DM, 2.72 percentage points $(P<0.0001)$ for HTN, and 3.25 percentage points $(P<0.0001)$ for $\mathrm{CHOL}$, relative to the control group (data not shown). For $\mathrm{PDC} \geq 80 \%$, results were similar in direction but higher in magnitude than the unrestricted population models; DID coefficients for DM, HTN, and CHOL were $0.231(P=0.085), 0.225(P<0.0001)$, and 0.315 $(P<0.0001)$, respectively.

\section{Discussion}

Evaluation of this multichannel adherence intervention found greater increases in adherence to HTN and CHOL for 2 health plans implementing the intervention compared with a group of health plans not employing adherence programs. Adherence to DM postintervention was similar between intervention and control groups for the primary analysis but was greater for the intervention group when we restricted the analysis to a subgroup of members with no history of 90-day use.
For the continuous adherence outcome, average adherence rates to medications prescribed for diabetes, hypertension, and cholesterol increased an average $0.57,2.0$, and 1.8 percentage points, respectively, for plans implementing the intervention. For the dichotomous adherence outcome, the intervention group had $10.7 \%, 12.5 \%$, and $11.3 \%$ increased odds of achieving adherence in the postperiod for DM, HTN, and CHOL, respectively. Assessing the continuous and dichotomous adherence outcomes provides useful information for health plans considering adherence interventions. The $\mathrm{PDC} \geq 80 \%$ binary outcome describes the ability of the intervention to increase the proportion of members reaching the adherence threshold used by CMS in performance ratings, and the continuous PDC outcome provides estimates of absolute adherence gain. Model results for both outcomes were qualitatively similar, suggesting our findings are robust.

Our results are similar in direction and magnitude to an observational study that observed greater effectiveness when it used a multicomponent approach compared with a single component intervention. In 2011, Jing et al. found messaging both providers and patients improved HTN and DM adherence by 1.8 percentage points in a Medicare population. ${ }^{40}$ Our findings of slightly greater DM adherence among older age 
TABLE 5 Intervention Effects on Adherence to Statins

\begin{tabular}{|c|c|c|c|c|c|c|c|c|c|}
\hline \multirow[b]{3}{*}{ Variable } & \multicolumn{3}{|c|}{ PDC (Continuous) } & \multicolumn{6}{|c|}{ PDC $\geq 80 \%$ (Binary) } \\
\hline & \multirow[b]{2}{*}{ Coefficient } & \multirow[b]{2}{*}{ SE } & \multirow[b]{2}{*}{$P$ Value } & \multirow[b]{2}{*}{ Coefficient } & \multirow[b]{2}{*}{ SE } & \multirow[b]{2}{*}{ OR } & \multicolumn{2}{|c|}{$95 \% \mathrm{CI}$} & \multirow[b]{2}{*}{$P$ Value } \\
\hline & & & & & & & Upper & Lower & \\
\hline Female (reference: male) & -0.008 & 0.002 & $<0.0001$ & -0.130 & 0.031 & 0.878 & 0.826 & 0.933 & $<0.0001$ \\
\hline \multicolumn{7}{|c|}{ Age group, years (reference: $<55$ years) } & 1.000 & 1.000 & \\
\hline $55-64$ & 0.026 & 0.007 & 0.000 & 0.273 & 0.101 & 1.313 & 1.077 & 1.601 & 0.0071 \\
\hline $65-74$ & 0.029 & 0.006 & $<0.0001$ & 0.294 & 0.091 & 1.341 & 1.122 & 1.604 & 0.0013 \\
\hline $75+$ & 0.030 & 0.006 & $<0.0001$ & 0.305 & 0.092 & 1.356 & 1.133 & 1.623 & 0.0009 \\
\hline \multicolumn{10}{|c|}{ Comorbidity count (reference: $<3$ ) } \\
\hline $3-4$ & 0.000 & 0.002 & 0.780 & 0.029 & 0.031 & 1.030 & 0.968 & 1.095 & 0.3519 \\
\hline $5-6$ & -0.005 & 0.002 & 0.033 & -0.051 & 0.041 & 0.951 & 0.877 & 1.030 & 0.218 \\
\hline $7-8$ & -0.006 & 0.004 & 0.131 & -0.087 & 0.064 & 0.917 & 0.809 & 1.039 & 0.1745 \\
\hline $9+$ & -0.010 & 0.007 & 0.168 & -0.221 & 0.106 & 0.802 & 0.652 & 0.987 & 0.037 \\
\hline New to therapy & -0.014 & 0.002 & $<0.0001$ & -0.405 & 0.039 & 0.667 & 0.618 & 0.720 & $<0.0001$ \\
\hline 90-day refill & 0.059 & 0.002 & $<0.0001$ & 0.644 & 0.033 & 1.904 & 1.784 & 2.031 & $<0.0001$ \\
\hline \multicolumn{10}{|c|}{ Number of target medication classes (reference: 1) } \\
\hline 2 & 0.008 & 0.002 & $<0.0001$ & 0.100 & 0.032 & 1.105 & 1.039 & 1.176 & 0.0016 \\
\hline 3 & 0.014 & 0.003 & $<0.0001$ & 0.177 & 0.046 & 1.194 & 1.091 & 1.305 & 0.0001 \\
\hline Low-income subsidy & -0.001 & 0.002 & 0.6310 & -0.054 & 0.040 & 0.947 & 0.875 & 1.025 & 0.1785 \\
\hline Time (reference: preperioda) & -0.007 & 0.001 & $<0.0001$ & -0.114 & 0.025 & 0.893 & 0.849 & 0.938 & $<0.0001$ \\
\hline Group (reference: control) & -0.012 & 0.003 & $<0.0001$ & -0.120 & 0.043 & 0.887 & 0.815 & 0.965 & 0.0053 \\
\hline Group $\times$ Time interaction ${ }^{\mathrm{b}}$ & 0.018 & 0.003 & $<0.0001$ & 0.221 & 0.049 & 1.247 & 1.132 & 1.374 & $<0.0001$ \\
\hline \multicolumn{10}{|c|}{$\begin{array}{l}\text { Note: Generalized linear models used to assess statistical difference between trea } \\
\text { outcome. } \\
\text { aPreperiod=April } 2012 \text { to March 2013; postperiod =April } 2013 \text { to March } 2014 \text {. } \\
\text { b Group } \times \text { Time interaction variable is difference-in-difference estimator. }\end{array}$} \\
\hline
\end{tabular}

groups and lower adherence among women are similar to a study of 379,533 Medicare members by Couto et al. (2014) that found a lower likelihood of attaining adherence in women $(\mathrm{OR}=0.896,95 \% \mathrm{CI}=0.869-0.924)$ and a lower likelihood of attaining adherence in members aged 50-64 years compared with 65-69 years $(\mathrm{OR}=0.827,95 \% \mathrm{CI}=0.791-0.865){ }^{41}$

We believe our analysis improves upon previous research methodologically because we limited the probability that our findings were confounded by probable rising adherence trends during the study period due to increased patient and prescriber awareness of the CMS star ratings and national adherence-promoting campaigns..$^{30-34}$ As a result of the CMS Star Ratings program and adherence campaigns, health plans have employed adherence interventions to improve quality of care and adherence rates; however, published findings of broad interventions applied within entire health plan populations are rare. The large majority of published adherence interventions are clinical trials conducted within small, controlled study populations and for durations of 3-6 months. ${ }^{6,42}$ Hence our historical prospective quasi-experimental design offers a higher standard of assessment than most observational designs reporting empirical evidence of adherence interventions among elderly populations. ${ }^{43}$
The greater adherence increases we observed among the intervention group are most likely attributable to the high prescriber response and acceptance rates for the 90-day intervention component. In the first year of the intervention, prescribers replied to $53.7 \%$ of faxes (prescriber-member-medication events), and $47.3 \%$ of the total 90-day prescription letters were approved by prescribers. Claim volume for 90-day refills for the 3 target classes increased pre- to postintervention by an average $52.2 \%$ for the intervention group compared with $30.8 \%$ for the control group. This increase indicates that the intervention was effective at switching the targeted members to 90-day prescriptions. For members switching to 90-day prescriptions, the additional medication supply translates into higher PDC and greater measured adherence.

The intervention may have extended beyond targeted members. Informing prescribers of the 90-day benefit may have increased 90-day prescribing for members not targeted by the program (i.e., spillover effect). For the refill reminder component, letters may have reminded and encouraged members to refill their medications and/or schedule a needed provider appointment. Similarly, prescriber-directed faxes may have prompted providers and staff to schedule office visits for their patients. Either of the above scenarios would lead to increased patient care, which is a positive consequence of the intervention. 
The differences in the observed treatment effect across the 3 medication classes may be explained by the lower proportion of 90-day claims filled for DM (47.8\%) compared with HTN (51.5\%) and CHOL (55.6\%). This difference in fulfillment indicates that prescribers were less likely to prescribe 90-day refills for DM medications, and therefore the intervention was less effective at switching members to a 90-day supply of these agents. Other possible reasons for the observed small change in adherence to DM over the study period could be due to the complexity of managing diabetes and associated difficulty in maintaining long-term adherence. National MA-PD plan adherence rates from 2012 to 2014 have increased at a lesser rate for DM (75\%-77\%) than rates for HTN (77\%-80\%) and CHOL (71\%-74\%). ${ }^{22}$ On the basis of these findings, members taking DM may benefit from more intensive clinical services to increase adherence.

Post hoc analyses revealed greater intervention effects within the subgroups of members targeted by the 90-day refill component (members without a 90-day claim). Restricting the analysis to these members found larger effects of the intervention for all 3 medication classes, suggesting the intervention was more effective for members with a 30-day prescription history.

Our evaluation also observed greater effectiveness among members using more than 1 targeted medication class (e.g., filling a DM and an HTN). Adherence improvements were greater in members using 2 of 3 classes (range $=0.8-2$. 1 percentage points) and greatest in members using all 3 classes (range $=1.4-3.2$ percentage points). This may be due to these members receiving multiple intervention exposures-multiple prescriber letters from the 90-day component or multiple refill reminders from the refill reminder program.

The purpose of this evaluation was to understand the overall effect of the intervention from the health plan perspective using an intent-to-treat approach; however, we also gauged potential intervention effects on the health plan's CMS quality performance ratings, which are measured on a calendar year basis. From 2012 to 2013, adherence rates increased 5.5 to 7.0 percentage points, which corresponded to increases in 1 to 2 star ratings for health plans implementing the intervention. ${ }^{12}$ These rates were larger than rates observed in our 1-year memberlevel analysis (0.6 to 2.0 percentage points).

We believe these differences are due to the population selected for measurement; CMS measures adherence for all members using medications in the calendar year, whereas our member-level analysis was restricted to members eligible during the study period that straddled the 2 calendar years. A review of membership records found that member enrollment increased significantly (53\%) from 2012 to 2013 for the plans implementing the intervention. Thus, a probable explanation for the large differences between CMS calendar-year rates and our member-level analysis may be due to reporting on different populations. The large increase in CMS-reported rates suggest that the intervention positively influenced new 2013 enrollees, a large group that was not captured in member-level analysis selection criteria. Further evaluation tracking adherence before and after receipt of the intervention would distinguish individual members' response, which could be used to provide information for targeted intervention efforts.

Our findings support the use of broad, multimodal interventions as an approach for MA-PD plans to improve population-level medication adherence using the methods measured and reported by CMS. The PDC methodology uses prescription drug event data to estimate actual medication consumption based on evidence that supports the use of pharmacy claims data as a proxy for true medication consumption. ${ }^{44,45}$ This intervention can be applied within large populations using relatively minimal resources and training compared with more intense behavioral or motivational interviewing approaches that require trained individuals to contact and engage members. The intervention was relatively quick to implement because it leveraged existing point-ofsale prescription adjudication processes and administrative pharmacy claims databases to identify targeted prescribers and members.

The benefits of 90-day supply via retail pharmacy settings from the patient perspective are increased medication access (by way of more supply of medication); the opportunity to synchronize maintenance medications; reduced transportation costs (fewer required pharmacy visits); and decreased out-ofpocket costs (copays for 90-days supply prescriptions equal those of two 30-day copays).

From the health plan perspective, increased 90-day prescription volume can lead to lower medication costs. Increased supply of medication also offers providers additional ways to help patients maintain therapy. This intervention can also complement existing interventions (e.g., behavioral counseling) to improve adherence. Systematic reviews of published adherence studies support using a multifactorial approach. ${ }^{6}$

The benefits of increased adherence to patients, health plans, and society include avoidable health care utilization and costs. A 2011 study by Roebuck et al. associated adherence with fewer inpatient hospital days per year $(3.14,3.41$, and $1.88)$ and fewer annual total health care costs $(\$ 5,824, \$ 5,170$, and $\$ 1,847$ ) for hypertension, diabetes, and hyperlipidemia, respectively, among patients older than 65 years. ${ }^{46}$

The benefits of increased quality performance ratings to health plans include publicized ratings and greater possibility for monetary and enrollment rewards. Performance ratings using data from the previous measurement period are posted on Medicare's Plan Finder website before Medicare's fall open enrollment period (October 15-December 7). CMS developed this site to allow members to compare health plans in hopes 
of driving enrollment to better-performing plans. Health plans receiving the highest overall star rating ( 5 stars) are able to enroll members year-round outside of the fall open enrollment period, and plans with an overall star rating of 4 or more stars have a greater probability of receiving QBPs.

\section{Limitations}

The following considerations should be regarded when interpreting our findings. First, a portion of the observed adherence improvements may be related to unmeasured factors or progressive adherence trends over the 2-year study period; however, we used a DID approach that limits confounding due to natural time trends. To examine the main assumption of the DID approach (i.e., the parallel trend assumption) and hence the merit of this approach, we measured adherence within a different medication class, antidepressants, during the study period and found no differential trends between the intervention and comparator group ( 0.7 vs. 0.6 percentage points). Models also included covariates traditionally associated with adherence to control for possible confounding in estimating intervention effects.

Second, we acknowledge that medication adherence is a series of behaviors influenced by multiple health system and patient-related factors. ${ }^{6,11,18}$ This intervention aimed to influence 2 commonly reported adherence barriers-medication access and patient forgetfulness. ${ }^{6,11,47}$ Adherence barriers reported in studies of elderly populations but not measured in this analysis include cost, regimen complexity, social reinforcement, and coordination of care.

Third, members' true adherence may differ from our estimated rates that used pharmacy claims to calculate proportion of days covered by medication. PDC is an objective, indirect measurement method that assumes members consume and refill medications as prescribed, but possession may not equate to consumption. If actual adherence is lower than assumed adherence, associations between the intervention and adherence may be overestimated. Conversely, patients may consume medication from sources outside of the health plan's pharmacy benefit (e.g., samples from providers or prescriptions filled by international pharmacies). This uncaptured use, although believed to be minimal, would result in underestimated adherence rates. PDC may also misrepresent actual adherence in scenarios in which discontinuation of therapy is deemed appropriate by one's provider or in the case in which members don't tolerate medication due to side effects.

We believe the above scenarios likely affect both groups and therefore would not differentially bias estimates of adherence for the intervention and comparison groups. Given the known limitations, the PDC methodology was developed by the Pharmacy Quality Alliance, was endorsed by the National Quality Forum, and is used by CMS in its Medicare star ratings. Ideally, additional adherence measurements to validate PDC would strengthen our assessment of members' medication adherence; however, subjective (e.g., patient self-reports) or other objective measures (e.g., biomarkers) were not available in this large study population.

Fourth, we acknowledge that PDC is positively associated with extended supply of medication, which was an aim of the intervention. To improve estimates of the intervention effect while accounting for 90-day prescriptions, our models included a control variable indicating the presence of 90-day refills in the baseline period.

Lastly, this intervention was implemented within 2 health plans. Applications of this intervention may not be generalizable to other MA-PD plans; however, our findings of positive effectiveness are consistent with evaluations of adherence interventions similar in modality within Medicare populations ${ }^{48}$ Replication of findings in similar populations would strengthen the generalizability of results. A priori randomized clinical trials would validate evidence of adherence intervention effects and could test associations with adherence and clinical outcomes.

\section{Conclusions}

This study found adherence improvements to antihypertensives and statins, but a modest change to oral antidiabetics, in 2 MA-PD plans implementing a prescriber and patient-directed intervention while adjusting for natural adherence trends and members' clinical and demographic characteristics. MA-PD plans can use broad multichannel interventions to address common adherence barriers and improve members' adherence to maintenance medications and health plan quality performance ratings.

\section{Authors}

R. SCOTT LESLIE, MPH, PhD, MedImpact Healthcare Systems, San Diego, California; TODD GILMER, PhD, Division of Health Policy and Department of Family Medicine and Public Health, University of California, San Diego; LOKI NATARAJAN, PhD, Department of Family Medicine and Public Health, Moores Cancer Center, University of California, San Diego; and MELBOURNE HOVELL, PhD, MPH, Graduate School of Public Health and Center for Behavioral Epidemiology and Community Health, University of California, San Diego.

AUTHOR CORRESPONDENCE: R. Scott Leslie, MPH, PhD, Health Outcomes Researcher, MedImpact Healthcare Systems, 10181 Scripps Gateway Ct., San Diego, CA 92131.

Tel.: 858.790.6685; E-mail:Scott.leslie@medimpact.com. 


\section{DISCLOSURES}

No funding was received in return for conducting this research. Leslie is an employee of MedImpact Healthcare Systems. The authors report no conflicts of interest.

Study concept was developed primarily by Leslie, along with Gilmer. Leslie took the lead in data collection, while data interpretation was performed by Leslie, Natarajan, and Gilmer. The manuscript was written primarily by Leslie, along with Gilmer and assisted by Hovell. Leslie, Gilmer, and Hovell revised the manuscript, with assistance from Natarajan.

\section{REFERENCES}

1. National Center for Chronic Disease Prevention and Health Promotion. National diabetes statistics report, 2014. Available at: www.cdc.gov/diabetes/ pdfs/data/2014-report-estimates-of-diabetes-and-its-burden-in-the-unitedstates.pdf. Accessed December 30, 2015.

2. Centers for Disease Control and Prevention. Vital signs: prevalence, treatment, and control of hypertension-United States, 1999-2002 and 20052008. MMWR Morb Mortal Wkly Rep. 2011;60(4):103-08. Available at: www. cdc.gov/mmwr/preview/mmwrhtml/mm6004a4.htm?s_cid=mm6004a4_w. Accessed December 30, 2015

3. Centers for Disease Control and Prevention. Vital signs: prevalence, treatment, and control of high levels of low-density lipoprotein cholesterolUnited States, 1999-2002 and 2005-2008. MMWR Morb Mortal Wkly Rep. 2011;60(4):109-14. Available at: www.cdc.gov/mmwr/preview/mmwrhtml/ mm6004a5.htm. Accessed December 30, 2015

4. U.S. Census Bureau. 2014 national population projections: summary tables. Available at: www.census.gov/population/projections/data/national/2014/summarytables.html. Accessed December 30, 2015.

5. Centers for Medicare \& Medicaid Services. Chronic conditions among Medicare beneficiaries. Chartbook: 2012 edition. Baltimore, MD. 2012. Available at: https://www.cms.gov/Research-StatisticsData-and-Systems/Statistics-Trends-and-Reports/Chronic-Conditions/ Downloads/2012Chartbook.pdf. Accessed December 30, 2015.

6. World Health Organization. Adherence to long-term therapies: evidence for action. Geneva, Switzerland. 2003. Available at: www.who.int/chp/knowledge/publications/adherence_full_report.pdf. Accessed December 30, 2015

7. Balkrishnan R, Rajagopalan R, Camacho FT, Huston SA, Murray FT, Anderson RT. Predictors of medication adherence and associated health care costs in an older population with type 2 diabetes mellitus: a longitudinal cohort study. Clin Ther. 2003;25(11):2958-71

8. Roebuck MC, Liberman JN, Gemmill-Toyama M, Brennan TA. Medication adherence leads to lower health care use and costs despite increased drug spending. Health Aff (Millwood). 2011;30(1):91-99.

9. Sokol MC, McGuigan KA, Verbrugge RR, Epstein RS. Impact of medication adherence on hospitalization risk and healthcare cost. Med Care. 2005;43(6):521-30

10. Ho PM, Rumsfeld JS, Masoudi FA, et al. Effect of medication nonadherence on hospitalization and mortality among patients with diabetes mellitus. Arch Intern Med. 2006;166(17):1836-41.

11. Ho PM, Bryson CL, Rumsfeld JS. Medication adherence: its importance in cardiovascular outcomes. Circulation. 2009;119(23):3028-35.

12. Centers for Medicare $\&$ Medicaid Services. Part $C$ and D performance data. Available at: https://www.cms.gov/Medicare/Prescription-DrugCoverage/PrescriptionDrugCovGenIn/PerformanceData.html. Accessed December 30, 2015.

13. Reid RO, Deb P, Howell BL, Shrank WH. Association between Medicare Advantage plan star ratings and enrollment. JAMA. 2013;309(3):267-74.
14. Centers for Medicare \& Medicaid Services. Fact sheet. November 10, 2010. Proposed changes to the Medicare Advantage and the Medicare prescription drug benefit programs for contract year 2012 and demonstration on quality bonus payments. Available at: https://www.cms.gov/apps/docs/ Fact-Sheet-2011-Landscape-for-MAe-and-Part-D-FINAL111010.pdf. Accessed December 30, 2015

15. The Henry J. Kaiser Family Foundation. Medicare Advantage plan star ratings and bonus payments in 2012. Data brief. November 2011. Available at: https://kaiserfamilyfoundation.files.wordpress.com/2013/01/8257.pdf. Accessed December 30, 2015.

16. Vollmer WM, Owen-Smith AA, Tom JO, et al. Improving adherence to cardiovascular disease medications with information technology. Am J Manag Care. 2014;20(11 Spec No. 17):SP502-10.

17. Cutrona SL, Choudhry NK, Fischer MA, et al. Modes of delivery for interventions to improve cardiovascular medication adherence. Am J Manag Care. 2010;16(12):929-42.

18. Haynes RB, Ackloo E, Sahota N, McDonald HP, Yao X. Interventions for enhancing medication adherence. Cochrane Database of Syst Rev. 2008;(2):CD000011.

19. Viswanathan M, Golin CE, Jones CD, et al. Closing the quality gap: revisiting the state of the science. Vol. 4: Medication adherence interventions: comparative effectiveness. Evidence report/technology assessment number 208. (Prepared by RTI International-University of North Carolina Evidence-based Practice Center under contract no. 290-2007-10056-I). AHRQ Publication No. 12-E010-EF. Rockville, MD: Agency for Healthcare Research and Quality. September 2012. Available at: www.ncbi.nlm.nih.gov/ books/NBK114350/. Accessed December 30, 2015.

20. Duru OK, Schmittdiel JA, Dyer WT, et al. Mail-order pharmacy use and adherence to diabetes-related medications. Am J Manag Care. 2010;16(1):33-40.

21. Zhang L, Zakharyan A, Stockl KM, Harada AS, Curtis BS, Solow BK. Mail-order pharmacy use and medication adherence among Medicare Part D beneficiaries with diabetes. J Med Econ. 2011;14(5):562-67.

22. Pringle J, Melczak M, Aldridge A, Snyder M, Smith R. Medication adherence and its relationship to the therapeutic alliance: results from an innovative pilot study within a community pharmacy MTM practice. Innovations in Pharmacy. 2011;2(1):1-16.

23. Stockl KM, Tjioe D, Gong S, Stroup J, Harada A, Lew HC. Effect of an intervention to increase statin use in Medicare members who qualified for a medication therapy management program. J Manag Care Pharm 2008;14(6):532-40. Available at: http://www.amcp.org/data/jmcp/ JMCPMaga_532-540.pdf.

24. Center for Medicare \& Medicaid Services. CMS Medicare health \& drug plan quality and performance ratings 2014 part C \& part D technical notes. Available at: https://www.cms.gov/Medicare/Prescription-Drug-Coverage/PrescriptionDrugCovGenIn/PerformanceData.html. Accessed December 30, 2015.

25. Leslie RS, Gwadry-Sridhar F, Thiebaud P, Patel BV. Calculating medication compliance, adherence and persistence in administrative pharmacy claims databases. Pharmaceut Programming. 2008;1(1):13-19.

26. Stuart B, Yin X, Davidoff A, et al. Impact of Part D low-income subsidies on medication patterns for Medicare beneficiaries with diabetes. Med Care. 2012:50(11):913-19.

27. Leslie RS, Erickson SC, Patel BV. Patient characteristics and medication burden affect adherence among seniors. Am J Pharm Benefits. 2014;6(4):91-96.

28. Center for Medicare \& Medicaid Services. Summary of comments to the request for comments on 2016 star ratings and beyond. Available at: https://www.cms.gov/Medicare/Prescription-Drug-Coverage/PrescriptionDrugCovGenIn/PerformanceData.html. Accessed December 30, 2015.

29. Gilmer T, Kronick R, Fishman P, Ganiats TG. The Medicaid Rx model: pharmacy-based risk adjustment for public programs. Med Care. 2001;39(11):1188-202. 
30. Bullman WR. Adherence improvement efforts are popping up all over. National Council on Patient Information and Education. April 2012. Available at: http://talkaboutrx.org/documents/Adherence\%20Efforts\%20Popping\%20 Up\%20All\%20Over\%204-13-12.pdf. Accessed December 31, 2015.

31. National Council on Patient Information and Education. Enhancing prescription medicine adherence: a national action plan. August 2007. Available at: http://www.talkaboutrx.org/documents/enhancing prescription_medicine_adherence.pdf. Accessed December 31, 2015.

32. National Consumers League. Script Your Future. Available at: http:// www.scriptyourfuture.org/about/. Accessed December 31, 2015.

33. National Community Pharmacists Association. Stick to the Script.org. Available at: http://www.stick2thescript.org/hcp/index.php/about. Accessed December 31, 2015.

34. American Pharmacists Association Foundation. Align my refills.com. Available at: http://www.alignmyrefills.com/. Accessed December 31, 2015

35. Liang KY, Zeger SL. Longitudinal data analysis using generalized linear models. Biometrika. 1986;73(1):13-22.

36. Zeger SL, Liang KY. An overview of methods for the analysis of longitudinal data. Stat Med. 1992;11(14-15):1825-39.

37. Diggle PJ, Heagerty PJ, Liang KY, Zeger SL. Analysis of Longitudinal Data. 2nd ed. Oxford: Oxford University Press; 2002.

38. Donohue JM, Zhang Y, Lave JR, et al. The Medicare drug benefit (Part D) and treatment of heart failure in older adults. Am Heart J. 2010;160(1):159-65.

39. Schabenberger O. Introducing the GLIMMIX procedure for generalized linear mixed models. Paper presented at: 2005 SAS Users Group International Conference (SUGI 30), April 10-13, 2005; Philadelphia, PA. Available at: http://www2.sas.com/proceedings/sugi30/196-30.pdf. Accessed December 31, 2015.
40. Jing S, Naliboff A, Kaufman MB, Choy M. Descriptive analysis of mail interventions with physicians and patients to improve adherence with antihypertensive and antidiabetic medications in a mixed-model managed care organization of commercial and Medicare members. J Manag Care Pharm. 2011;17(5):355-66. Available at: http://www.jmcp.org/doi/ pdf/10.18553/jmcp.2011.17.5.355.

41. Couto JE, Panchal JM, Lal LS, et al. Geographic variation in medication adherence in commercial and Medicare part D populations. J Manag Care Spec Pharm. 2014;20(8):834-42. Available at: http://www.jmcp.org/doi/ pdf/10.18553/jmcp.2014.20.8.834.

42. Osterberg L, Blaschke T. Adherence to medication. N Engl J Med. 2005;353(5):487-97.

43. Conn VS, Hafdahl AR, Cooper PS, Ruppar TM, Mehr DR, Russell CL. Interventions to improve medication adherence among older adults: meta-analysis of adherence outcomes among randomized control trials. Gerontologist. 2009;49(4):447-62.

44. Steiner JF, Prochazka AV. The assessment of refill compliance using pharmacy records: methods, validity, and applications. J Clin Epidemiol. 1997;50(1):105-16.

45. Lau HS, de Boer A, Beuning KS, Porsius A. Validation of pharmacy records in drug exposure assessment. J Clin Epidemiol. 1997;50(5):619-25.

46. Roebuck MC, Liberman JN, Gemmill-Toyama M, Brennan TA. Medication adherence leads to lower health care use and costs despite increased drug spending. Health Aff (Millwood). 2011;30(1):91-99.

47. AlGhurair SA, Hughes CA, Simpson SH. Guirguis LM. A systematic review of patient self-reported barriers of adherence to antihypertensive medications using the world health organization multidimensional adherence model. J Clin Hypertens (Greenwich). 2012;14(12):877-86.

48. Leslie RS, Tirado B, Patel BV, Rein PJ. Evaluation of an integrated adherence program aimed to increase Medicare Part D star rating measures. J Manag Care Spec Pharm. 2014;20(12):1193-203. Available at: http://www. jmcp.org/doi/pdf/10.18553/jmcp.2014.20.12.1193. 